\title{
НАКОПЛЕННЫЙ ВРЕД КАК ИСТОЧНИК НЕГАТИВНОГО ВОЗДЕЙСТВИЯ НА ОКРУЖАЮЩУЮ СРЕДУ
}

\section{ACCUMULATED HARM AS \\ A SOURCE OF NEGATIVE IMPACT ON THE ENVIRONMENT}

\section{T. Nedova}

Summary. This article deals with the issues of determining and legal regulation of accumulated harm as a source of negative impact on the environment. It is noted that it is problematic for most cases to determine the appropriate subject of responsibility. It is proposed to distinguish not the object of $\mathrm{HB}$ with the object of waste disposal, but to solve the problem of its elimination by searching and establishing the responsible entity.

Keywords: accumulated harm, object, waste, law, legal regulation, reliable information, environment, harm.

\author{
Недова Наталья Сергеевна \\ К.ю.н., доцент, Российский университет \\ транспорта, г. Москва \\ nedova.nat@mail.ru
}

Аннотация. В настоящей статье рассматриваются вопросы определения и правового регулирования накопленного вреда (НB) как источника негативного воздействия на окружающую среду. Отмечено, что представляется проблематичным для большинства случаев определение надлежащего субъекта ответственности. Предлагается разграничивать не объект НВ с объектом размещения отходов, а решать проблему его ликвидации путем поиска и установления ответственного субъекта.

Ключевые слова: накопленный вред, объект, отходы, закон, правовое регулирование, достоверная информация, окружающая среда, вред.

население должно быть оповещено о состоянии окружающей среды, ведь она постоянно оказывает на него прямое воздействие. И в данном случае особое внимание следует уделять накопленному вреду, поскольку он является одним из источников негативного воздействия на окружающую среду.

Накопленный вред, как комплексный институт экологического права проецируются на значительное количество эколого-правовых и иных отношений, однако, сложно найти наименее теоретически разработанную правовую категорию в российском праве, чем накопленный вред.

Накопленный вред (далее - НВ) представляет собой некий вид экологического вреда, причиненного в результате предшествующей деятельности природопользователей, которые в свое время не устранили негативные последствия своей деятельности на окружающую среду (далее - ОС), хотя владельцы таких предприятий по различным причинам на сегодня, как правило, отсутствуют. Иными словами, не НВ как таковой становится объектом права, а только «резервуар» в виде того пространства или акватории, где он помещен или размещен в виде отхода или объекта капитального строительства.

Не случайно федеральный закон от 10.01.2002 N7Ф3 «Об охране окружающей среды» [2] (далее - Закон) определяет очень широко и не ограничивая как сам 
объект НВ, пространственно включающий в себя любой из природных объектов (и их совокупность), так и любой источник НВ - объекты размещения отходов и заброшенные объекты капстроительства, причем без уточнения, ограничения по видам таких объектов. Более того, представляется, что детализация и тем более классификация большинства источников НВ и их объектов по видам не только практически нецелесообразна, но и подчас невозможна.

Каждый $\mathrm{HB}$, как источник негативного воздействия на ОС, индивидуален, и, соответственно, каждый такой объект неповторим, что требует принятия решения уполномоченного государственного органа по его признанию в качестве объекта НВ и ликвидации в силу его особенностей. Разнятся также качество (состав загрязняющих характеристик), масштаб влияния на ОС и здоровье людей, эколого-правовые и технологические характеристики объекта НВ, способы его ликвидации, включая расчет затрат, и пр.

Закрепляя рассматриваемую категорию, Закон практически вводит правовые критерии ответственности за прошлый вред природопользователя:

а) причинная связь с его прежней хозяйственной деятельностью или его предшественников,

б) невыполнение обязанности по устранению экологического вреда в полном объеме.

По деликту предприятие-загрязнитель является потенциально ответственным за весь вред (ущерб), как уже возникший, так и могущий возникнуть в будущем в результате нарушения требований законодательства об охране ОС. К таким нарушениям в первую очередь относятся превышение выбросов (сбросов) по массе загрязняющих веществ, сброс сточных вод без очистки в водные объекты, нарушения требований по рекультивации земель, размещение несанкционированных отходов и др.

Удобство рассматриваемой правовой конструкции «объект НВ» заключается преимущественно лишь во введении критериев, облегчающих установление правовой связи объекта НВ с ответственным $(-и)$ за выполнение обязательств по ликвидации источника НВ в прошлом. Поэтому ретроспективная ответственность на практике будет оправдана в тех ограниченных ситуациях, если нынешний собственник объекта НВ, не будучи причинителем вреда, вправе предъявить требование о компенсации понесенных расходов к его причинителям в рамках правопреемства. Если таковой существует, то юридически упорядочивается путь к запуску восстановительных, ликвидационных мероприятий. Однако, поскольку в большинстве случаев такие объекты в настоящее время не имеют собственника (владельца), вышеприведенные критерии требуют развития и уточнения.

Таким образом, представляется проблематичным для большинства случаев определение надлежащего субъекта ответственности, что лишает целесообразности использования деликта.

В части распределения бремени ответственности между государством и загрязнителем отметим, что соответствующие законодательные подходы в мировой практике к устранению НВ варьируются, помимо использования ретроспективной ответственности загрязнителя, вокруг адаптации концессионной модели (или государственно-частного партнерства) [3. С. 17-21], либо принятием государством на себя основной степени тяжести ответственности, либо же комбинации вышеуказанных подходов. Определение одного из указанных вариантов зависит от множества факторов, включая масштабы НВ, уровень развития экономики и долю госсектора в экономике, состояние экологических законодательства, культуры, страхования и т.д.

В связи с чем представляется целесообразным в будущем сосредоточиться на последнем варианте, для чего потребуется поиск баланса публично- и частноправовых начал, закрепление максимально гибкой модели распределения ответственности участников отношений по ликвидации НB.

Допустим, если установить владельца объекта НВ представляется проблематичным, государство берет ответственность на себя путем принятия на законодательном и правительственном уровнях решений о выделении бюджетных и иных ресурсов под специальные приоритетные государственные проекты и федеральные программы. Как известно, большинство выявленных объектов НВ формировались в советский период десятилетиями экстенсивного природопользования без учета экологических последствий в условиях плановой экономики различными государственными предприятиями, включая военно-промышленный комплекс. При обнаружении объекта НВ уполномоченный государственный орган оценивает, можно ли найти ответственное лицо и может ли быть возмещен экологический вред.

В России, как и в большинстве стран, ответственность за расходы по ликвидации такого объекта возлагается на того, кто в настоящий момент владеет территориями, где размещен такой объект, так как по закону собственник (владелец) несет ответственность в том числе и за риски, источником которых является его имущество, а также обязан предпринимать необходимые меры по предотвращению этих рисков и негативных послед- 
ствий. Далее, именно собственник или владелец имеет доступ к территориям, которые необходимо очистить.

Далее, рассматривая соотношение понятия объекта НВ и понятие «отходы», отметим, что они по логике должны соотноситься как пересекающиеся множества, причем в точке пересечения должны находиться именно отходы сырьевого сектора. В частности, это отходы горной добычи, переработки, при определенных обстоятельствах техногенные образования, которые могут выступать параллельно как активом (сырьем), так и пассивом (отходом) в период подготовки и проведения ликвидационных мероприятий, а также другие виды отходов. Иными словами, те объекты несанкционированного размещения отходов прошлой деятельности, которые не имеют надлежащего собственника, охватываются понятием объекта НВ.
Определенная их часть, подлежащая ликвидации в первоочередном порядке, включается, соответственно, в государственный реестр объектов НВ [3. С. 18]. Остальные из выявленных объектов НВ попадают в правовое поле законодательства об обращения с отходами и, соответственно, законодательства о НВ. В определенных ситуациях, если последний владелец предприятия не является причинителем всего или части $\mathrm{HB}$, разграничение ответственности за очистку объекта проводится только по условной дате, установленной законодательством.

На основании изложенного сделаем вывод о том, что в связи с этим представляется целесообразным разграничивать не объект НВ с объектом размещения отходов, а решать проблему его ликвидации путем поиска и установления ответственного субъекта, либо признания таковым предложенными нами способами.

\section{ЛИТЕРАТУРА}

1. К Конституция Российской Федерации (принята всенародным голосованием 12.12.1993 с изменениями, одобренными в ходе общероссийского голосования 01.07.2020) // СПС «Консультант Плюс».

2. Федеральный закон от 10.01.2002 N7-Ф3 (ред. от 09.03.2021) «06 охране окружающей среды» // СПС «Консультант Плюс».

3. Новикова Е.В. Концессионные механизмы решения накопленного вреда: правовые аспекты // Нефть, газ и право. 2018. N4. С. $17-21$.

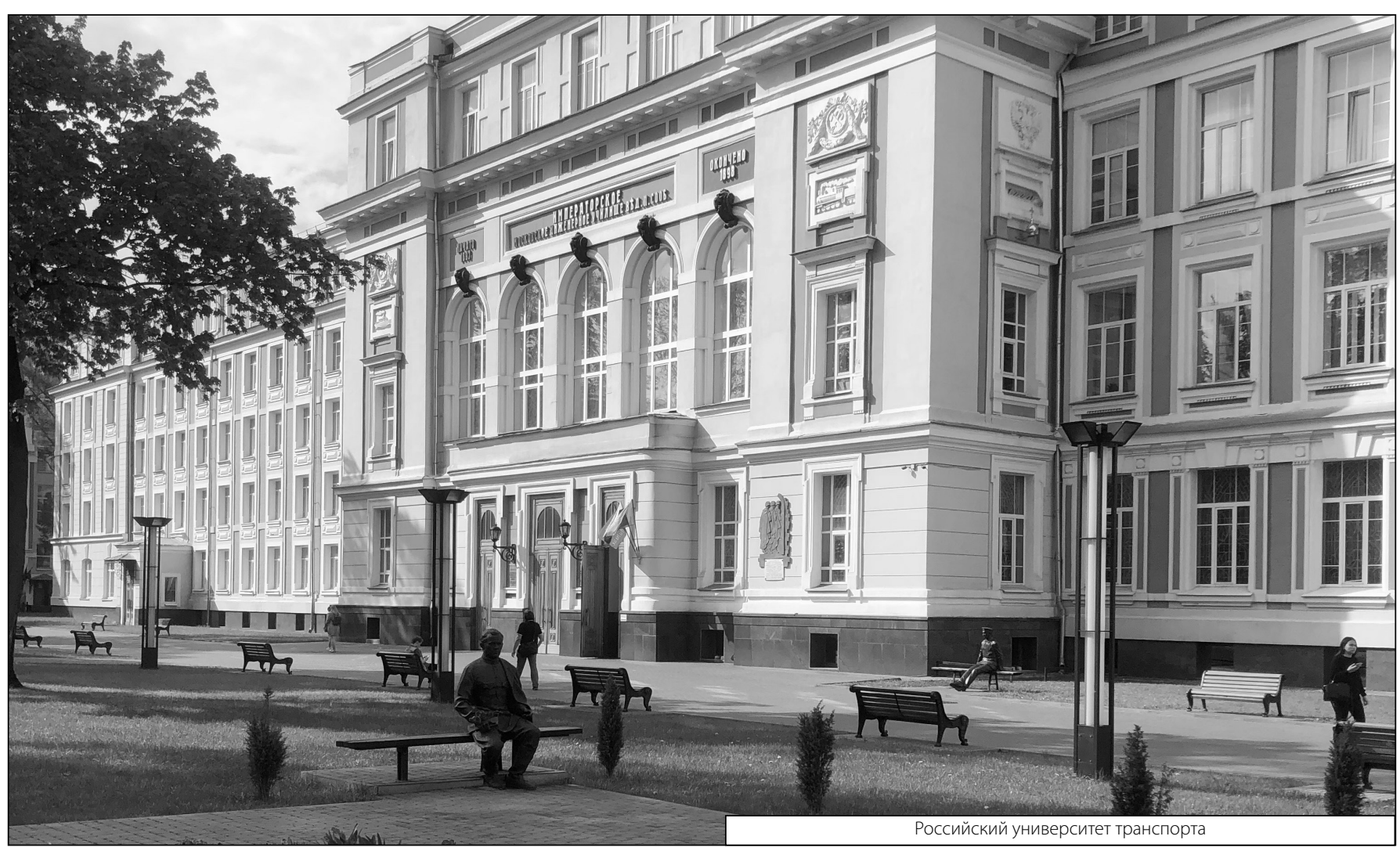

